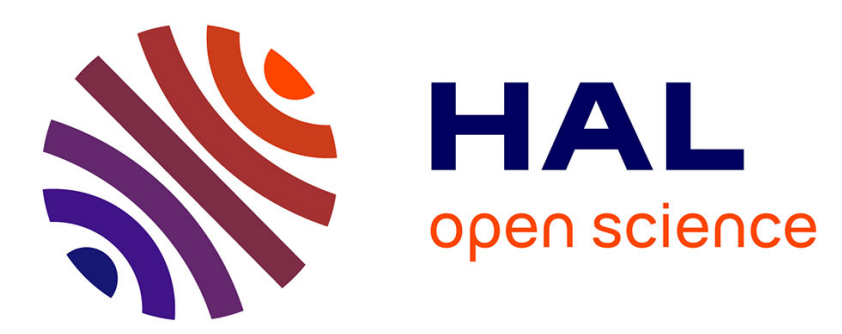

\title{
Delivery of adjuvant sequential dose-dense FEC-Doc to patients with breast cancer is feasible, but dose reductions and toxicity are dependent on treatment sequence
}

H. Wildiers, L. Dirix, P. Neven, A. Prové, P. Clement, P. Squifflet, F. Amant, T. Skacel, R. Paridaens

\section{To cite this version:}

H. Wildiers, L. Dirix, P. Neven, A. Prové, P. Clement, et al.. Delivery of adjuvant sequential dosedense FEC-Doc to patients with breast cancer is feasible, but dose reductions and toxicity are dependent on treatment sequence. Breast Cancer Research and Treatment, 2008, 114 (1), pp.103-112. 10.1007/s10549-008-9970-z . hal-00478329

\section{HAL Id: hal-00478329 \\ https://hal.science/hal-00478329}

Submitted on 30 Apr 2010

HAL is a multi-disciplinary open access archive for the deposit and dissemination of scientific research documents, whether they are published or not. The documents may come from teaching and research institutions in France or abroad, or from public or private research centers.
L'archive ouverte pluridisciplinaire HAL, est destinée au dépôt et à la diffusion de documents scientifiques de niveau recherche, publiés ou non, émanant des établissements d'enseignement et de recherche français ou étrangers, des laboratoires publics ou privés. 


\title{
Delivery of adjuvant sequential dose-dense FEC-Doc to patients with breast cancer is feasible, but dose reductions and toxicity are dependent on treatment sequence
}

\author{
H. Wildiers $\cdot$ L. Dirix $\cdot$ P. Neven $\cdot$ A. Prové · \\ P. Clement $\cdot$ P. Squifflet $\cdot$ F. Amant . \\ T. Skacel $\cdot$ R. Paridaens
}

Received: 22 November 2007 / Accepted: 5 March 2008/Published online: 16 March 2008

(C) Springer Science+Business Media, LLC. 2008

\begin{abstract}
Introduction This study prospectively investigates the impact of dose densification and altering sequence of fluorouracil, epirubicin and cyclophosphamide $\left[\mathrm{FEC}_{100}\right]$ and docetaxel [Doc] on dose delivery and tolerability of adjuvant chemotherapy in breast cancer patients. Methods 117 patients with high-risk primary operable breast cancer were randomized (1:1:2:2) to conventional (three cycles of 3-weekly $\mathrm{FEC}_{100}$ then three cycles of 3weekly Doc $100 \mathrm{mg} / \mathrm{m}^{2}$ or reverse sequence) or dose-dense (dd) treatment (four 10- to 11-day cycles of $\mathrm{FEC}_{75}$ then four 2-weekly cycles of Doc $75 \mathrm{mg} / \mathrm{m}^{2}$, or the reverse). In the dd arms, pegfilgrastim was given on day 2 of each
\end{abstract}

H. Wildiers · P. Neven · F. Amant · R. Paridaens

Multidisciplinary Breast Center, University Hospitals Leuven,

Leuven, Belgium

H. Wildiers $\cdot$ P. Clement $\cdot$ R. Paridaens

Department of General Medical Oncology,

University Hospitals Leuven, Leuven, Belgium

H. Wildiers ( $\square$ )

Multidisciplinary Breast Centre, University Hospital

Gasthuisberg, Herestraat 49, 3000 Leuven, Belgium

e-mail: hans.wildiers@uzleuven.be

L. Dirix · A. Prové

Department of Medical Oncology, St-Augustinus,

Wilrijk, Belgium

P. Squifflet

IDDI, Ottignies Louvain-la-Neuve, Belgium

T. Skacel

Medical Affairs, Amgen (Europe) GmbH, Zug, Switzerland

T. Skacel

Department of Medicine, Charles University, Prague,

Czech Republic cycle, but only as secondary prophylaxis in conventional arms. Results The primary endpoint was the proportion of patients completing intended cycles at relative dose intensity $\geq 85 \%$ and this was achieved by $95 \%$ of patients in each group except for the ddDoc $\rightarrow$ FEC group (90\%). Dose intensity in the dd arms increased by $48 \%$ for FEC and $11 \%$ for docetaxel, compared with the conventional arms (both $P<0.001$ ). Doc dose reductions were more frequent with dd treatment and when Doc was given after FEC. Grade 3-4 neutropenia was significantly more frequent with conventional treatment, while fatigue and handfoot syndrome were numerically more common with dd treatment, particularly when Doc was given after FEC. Discussion Delivery of adjuvant sequential ddFEC and Doc is feasible with growth factor support, and chemotherapy sequence appeared to affect delivery of target doses and toxicity.

Keywords Breast cancer - Chemotherapy ·

Cyclophosphamide - Docetaxel - Dose densification .

Epirubicin · Fluorouracil · Granulocyte

colony-stimulating factor - Pegfilgrastim - Relative dose intensity

\section{Introduction}

For patients with breast cancer, improvements in adjuvant chemotherapy regimens-from CMF (cyclophosphamide, methotrexate and fluorouracil) to anthracyclines (A) and taxanes (T) - have led to substantial improvement in outcomes [1, 2]. More recently, studies have shown that further improvements can be achieved by administering the same amount of chemotherapy over a shorter period (called dose-dense [dd] therapy). This contrasts with previous 
attempts to deliver substantially higher drug doses requiring hematopoietic reconstitution (called high-dose chemotherapy) which failed to improve outcome [3]. The importance of dosing is illustrated by studies showing that reduced dosing (e.g., resulting from delays or reductions) is a strong, independent predictor of reduced disease-free survival (DFS) and overall survival (OS) [4-7]. Dose-dense therapy generally requires the use of growth factors, such as granulocyte colony-stimulating factor (G-CSF), to reduce the risk of haematological adverse events. The feasibility of dose densification of a number of chemotherapy regimens in patients with breast cancer has been investigated, including epirubicin (E)/paclitaxel, with or without CMF [8-12], ET-CMF [13] and TEC [14].

In a comparison of dd with conventional schedules of sequential and concurrent $\mathrm{A}, \mathrm{C}$ and paclitaxel chemotherapy in 2005 patients with node-positive breast cancer, dd treatment significantly improved DFS and OS compared with conventional treatment [15]. The regimen used may not, however, be the optimal AT combination. For example, meta-analysis has shown that addition of paclitaxel to AC may be associated with only limited survival gain compared with AC alone. Moreover, the Programme Adjuvant Cancer du Sein (PACS) 01 study, comparing FEC with FEC-Docetaxel (Doc), and Breast Cancer International Research Group (BCIRG) 001 study, comparing FAC with DocAC, have shown significant and relevant survival benefits for Doc [2]. In addition, Doc has been shown to increase OS in metastatic breast cancer compared with paclitaxel [16], while high-dose adjuvant $\mathrm{FEC}_{100}$ improved OS compared with a conventionally dosed anthracycline regimen [17].

Dose densification of FEC has been assessed in a study in which $\mathrm{FEC}_{60}$ was given at 3-weekly or 2-weekly intervals [18]. Dose-dense FEC was well tolerated and associated with a modest improvement in outcomes, although epirubicin $60 \mathrm{mg} / \mathrm{m}^{2}$ is probably inferior to the $100 \mathrm{mg} / \mathrm{m}^{2}$ used in current adjuvant FEC regimens. Densification of $\mathrm{FEC}_{100}$ from 3-weekly to 2-weekly with G-CSF support has, however, been found unfeasible as a result of high toxicity, including pericardial effusion, pneumonitis and frequent hospitalisations [19, 20]. Decreasing peak plasma levels of doxorubicin by continuous infusion has also been shown to reduce cardiotoxicity [21]. Dose densification of Doc therapy is feasible, as demonstrated in a study of biweekly doxorubicin $50 \mathrm{mg} / \mathrm{m}^{2}$ and Doc $75 \mathrm{mg} / \mathrm{m}^{2}$ [22]. Studies with Doc $100 \mathrm{mg} / \mathrm{m}^{2}$ biweekly have shown, however, that this regimen is associated with high toxicity that is mainly skin-related [23, 24]. Therefore, an alternative regimen was chosen for investigation in the present study, with the doses of cytostatic agents fractionated into more frequent administrations $\left(4 \times \mathrm{FEC}_{75}\right.$ and $4 \times$ Doc $75 \mathrm{mg} / \mathrm{m}^{2}$ rather than $3 \times \mathrm{FEC}_{100}$ and $3 \times$ Doc $100 \mathrm{mg} / \mathrm{m}^{2}$ ).
In most adjuvant trials, taxanes are added after anthracyclines (e.g. AC $\rightarrow \mathrm{T}$ or $\mathrm{FEC} \rightarrow$ Doc). It may, however, be better to administer the most active chemotherapeutic agent first, as doxorubicin appears to be more effective when administered before CMF than after CMF [25]. Moreover, Doc $100 \mathrm{mg} / \mathrm{m}^{2}$ generates significantly higher response rates than doxorubicin $75 \mathrm{mg} / \mathrm{m}^{2}$ in metastatic breast cancer [26]. Using Doc before anthracyclines might therefore be beneficial compared with the reversed sequence.

The aim of the present study was to investigate the feasibility of sequenced, densified FEC- and Doc-based regimens in patients with primary operable high-risk breast cancer. The study was also designed to assess impact of sequence of Doc and FEC on chemotherapy delivery and safety.

\section{Methods}

Study design

This randomised, open-label, Phase II trial was carried out at two centres in Belgium. Registration and randomisation of patients was carried out centrally via e-mail or fax, and patients were stratified for age ( $<50$ years and $\geq 50$ years).

Patients were randomised (1:1:2:2) to one of four treatment arms (Fig. 1). In two treatment arms, patients received conventional regimens of sequential FEC (fluorouracil $500 \mathrm{mg} / \mathrm{m}^{2}$ by i.v. bolus or infusion, epirubicin $100 \mathrm{mg} / \mathrm{m}^{2}$ by $30 \mathrm{~min}$ i.v. infusion and cyclophosphamide $500 \mathrm{mg} / \mathrm{m}^{2}$ by i.v. bolus or infusion) and Doc $\left(100 \mathrm{mg} / \mathrm{m}^{2}\right.$ by 60 -min i.v infusion). Patients with body surface greater

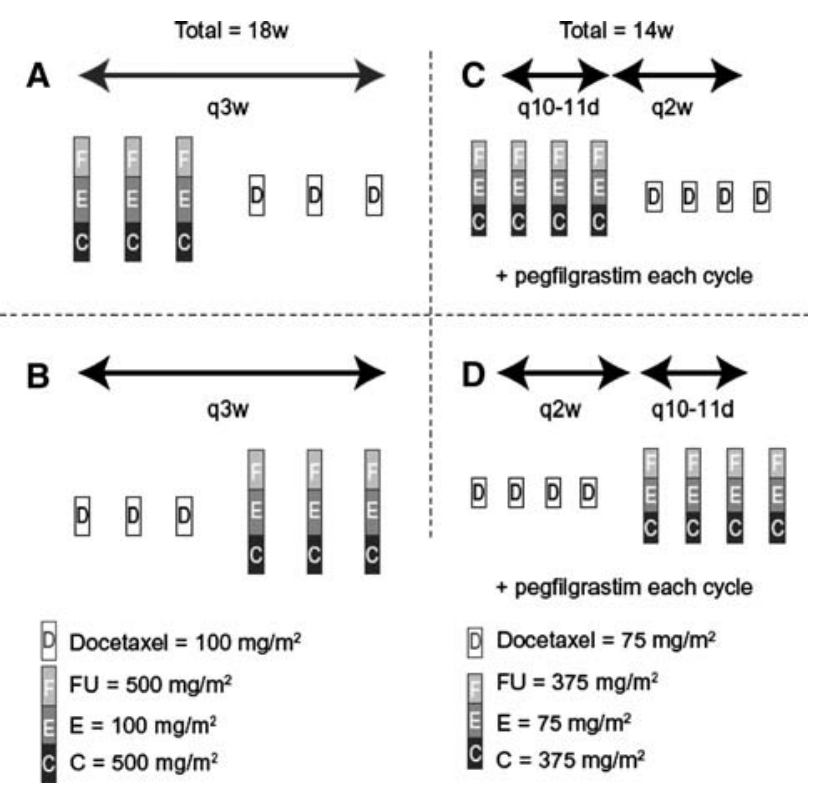

Fig. 1 Study design 
than $2 \mathrm{~m}^{2}$ were treated with a dose calculated on the basis of $2 \mathrm{~m}^{2}$. Chemotherapy was given on day 1 of each 21-day cycle without primary growth factor support. The total planned duration of treatment was 18 weeks. In Arm A, three cycles of conventional FEC were followed by three cycles of conventional Doc, while Arm B consisted of the reverse sequence of three cycles of conventional Doc followed by three cycles of conventional FEC. The third and fourth treatment arms consisted of two dd regimens of sequential FEC (fluorouracil $375 \mathrm{mg} / \mathrm{m}^{2}$ by i.v. bolus or infusion, epirubicin $75 \mathrm{mg} / \mathrm{m}^{2}$ by 30 -min i.v. infusion and cyclophosphamide $375 \mathrm{mg} / \mathrm{m}^{2}$ by i.v. bolus or infusion) and Doc $75 \mathrm{mg} / \mathrm{m}^{2}$. FEC was given on day 1 of each 10- to 11-day cycle and Doc was given on day 1 of each 14-day cycle. Pegfilgrastim Neulasta $^{\circledR}$, Amgen Inc, Thousand Oaks, CA, USA) was given as a single subcutaneous injection on day 2 of each study cycle (6 $\mathrm{mg}$ fixed dose, as $0.6 \mathrm{ml}$ of a $10 \mathrm{mg} / \mathrm{ml}$ solution). The total planned duration of treatment was 14 weeks. In Arm C, patients received four cycles of dd FEC followed by four cycles of dd Doc, while in Arm D patients received four cycles of dd Doc followed by four cycles of dd FEC.

In patients receiving either conventional regimen (Arms A and B), pegfilgrastim was allowed only for secondary prophylaxis of febrile neutropenia or prolonged Grade IV neutropenia. In the event of febrile neutropenia or prolonged Grade 4 neutropenia, pegfilgrastim or filgrastim (Neupogen ${ }^{\circledR}$, as above) could be given for treatment, and pegfilgrastim was further administered on day 2 of each subsequent cycle of chemotherapy.

Ethical Review Boards approved the protocol at each centre and all patients provided written, informed consent.

Dose adjustments and delays

No dose escalation was permitted during the study. If haematological toxicity necessitated a delay, treatment was restarted at the beginning of the new cycle immediately after recovery of neutrophils $\left(\geq 1 \times 10^{9} / 1\right)$ and platelets $\left(\geq 100 \times 10^{9} / 1\right)$. Haematological toxicities that required protocol-specified dose reduction were absolute neutrophil count (ANC) $<0.5 \times 10^{9} / 1$ for $>5$ days; ANC $<0.1 \times 10^{9} /$ 1 for $>3$ days; febrile neutropenia (i.e. temperature $\geq 38.5^{\circ} \mathrm{C}$ and ANC $<1.0 \times 10^{9} / 1$ ); platelets $<25 \times 10^{9} / 1$. In patients receiving conventional treatment, FEC and Doc doses were reduced to $375 \mathrm{mg} / \mathrm{m}^{2}, 75 \mathrm{mg} / \mathrm{m}^{2}, 375 \mathrm{mg} / \mathrm{m}^{2}$ and $75 \mathrm{mg} / \mathrm{m}^{2}$, respectively. In those receiving dd treatment, the respective reduced doses were $300 \mathrm{mg} / \mathrm{m}^{2}$, $60 \mathrm{mg} / \mathrm{m}^{2}, 300 \mathrm{mg} / \mathrm{m}^{2}$ and $60 \mathrm{mg} / \mathrm{m}^{2}$. Dose reductions related to non-haematological toxicity depended on the grade of the adverse event (Grade 0-2 or Grade 3 nausea/ vomiting: planned dose; Grade 3 [except nausea/vomiting and alopecia]: dose reduced as for haematological toxicity or hold treatment; Grade 4: hold treatment).

Treatment could be postponed for up to 2 weeks if haematological or non-haematological toxicity had not resolved by planned day 1 of the subsequent cycle. Patients were discontinued from the study if the start of a given cycle was postponed as a result of toxicity for $>2$ weeks.

\section{Patients}

Patients included in the study were aged $\geq 18$ years and $<70$ years with histologically proven early breast cancer requiring adjuvant chemotherapy (lymph node positive or other features of high risk according to St-Gallen criteria). Radiotherapy was to be performed after adjuvant chemotherapy and according to each centre's policy. Patients were required to have good performance status (Eastern Cooperative Oncology Group [ECOG] scale: 0-1 [27]), normal cardiac function and adequate organ function. Major exclusion criteria included previous systemic anticancer therapy or radiation therapy for breast cancer.

\section{Endpoints and analysis}

The primary endpoint was the number of patients in each arm who completed all intended cycles at an overall relative dose intensity (RDI) of at least $85 \%$ of the global regimen. Dose intensity $\left(\mathrm{DI}_{\mathrm{ref}}\right)$ was also calculated as a percentage of a reference value, defined as the dose intensity achieved in Arm A or B for a patient who received all intended doses with no cycle delay or dose reduction. Secondary endpoints included the incidence of dose delays ( $\geq 1$ day) and dose reductions of planned chemotherapy regimens that resulted from adverse events (haematological and non-haematological) by treatment arm and by dd vs. conventional administration. Toxicity and tolerability were also evaluated, with a focus on incidence of neutropenia and febrile neutropenia Grade 3-4 by treatment arm and by dd vs. conventional administration. Toxicity was assessed before each cycle using the NCI Common Toxicity Criteria (CTC) (Version 3.0) [28], and adverse events were recorded throughout.

\section{Sample size}

This trial aimed to prove that it was possible to administer at least $85 \%$ of the overall RDI in a large proportion of patients. Specifically, the trial was powered to separate, within each arm, a null hypothesis of at most $75 \%$ of patients reaching the primary endpoint, versus the alternative of at least $90 \%$ of patients reaching the primary endpoint, using a 2-step Simon design, with alpha 0.05 and power $80 \%$. Patients receiving conventional chemotherapy 
Table 1 Baseline demographics and disease characteristics

\begin{tabular}{|c|c|c|c|c|}
\hline & \multicolumn{2}{|l|}{ Conventional } & \multicolumn{2}{|l|}{ Dose-dense } \\
\hline & $\begin{array}{l}\text { A } \\
\text { FEC-Doc }(n=19)\end{array}$ & $\begin{array}{l}\text { B } \\
\text { Doc-FEC }(n=20)\end{array}$ & $\begin{array}{l}\text { C } \\
\text { FEC-Doc }(n=39)\end{array}$ & $\begin{array}{l}\text { D } \\
\text { Doc-FEC }(n=39)\end{array}$ \\
\hline Age (years), mean $\pm \mathrm{SD}$ & $48.9 \pm 9.7$ & $48.0 \pm 8.6$ & $48.6 \pm 8.5$ & $49.2 \pm 10.0$ \\
\hline \multicolumn{5}{|l|}{ Age stratification, $n(\%)$} \\
\hline$<50$ years & $10(53)$ & $10(50)$ & $20(51)$ & $20(51)$ \\
\hline$\geq 50$ years & $9(47)$ & $10(50)$ & $19(49)$ & $19(49)$ \\
\hline Height $(\mathrm{cm})$, mean \pm SD & $163.7 \pm 8.5$ & $164.4 \pm 7.7$ & $163.8 \pm 5.5$ & $164.8 \pm 6.2$ \\
\hline Weight $(\mathrm{kg})$, mean $\pm \mathrm{SD}$ & $63.6 \pm 12.6$ & $64.9 \pm 10.2$ & $67.7 \pm 15.5$ & $65.6 \pm 9.7$ \\
\hline \multicolumn{5}{|l|}{ Histology, $n(\%)$} \\
\hline Ductal & $16(84)$ & $18(90)$ & $33(85)$ & $35(90)$ \\
\hline Lobular & $2(11)$ & $1(5)$ & $4(10)$ & $1(3)$ \\
\hline Other & $1(5)$ & $1(5)$ & $2(5)$ & $3(7)$ \\
\hline \multicolumn{5}{|l|}{ Stage at time of diagnosis, $n(\%)$} \\
\hline I & $5(26)$ & $4(20)$ & $2(5)$ & $11(28)$ \\
\hline II & $9(47)$ & $10(50)$ & $31(79)$ & $20(51)$ \\
\hline III & $5(26)$ & $6(30)$ & $6(15)$ & $8(21)$ \\
\hline Number of lymph nodes involved, mean \pm SD & $4.9 \pm 9.7$ & $4.8 \pm 7.5$ & $4.2 \pm 6.9$ & $2.8 \pm 5.3$ \\
\hline \multicolumn{5}{|l|}{ Oestrogen receptor status, $n(\%)$} \\
\hline Negative & $5(26)$ & $6(30)$ & $8(21)$ & $14(36)$ \\
\hline Positive & $14(74)$ & $14(70)$ & $31(79)$ & $25(64)$ \\
\hline \multicolumn{5}{|l|}{ Progesterone receptor status, $n(\%)$} \\
\hline Negative & $3(16)$ & $6(30)$ & $8(21)$ & $12(31)$ \\
\hline Positive & $16(84)$ & $14(70)$ & $31(79)$ & $27(69)$ \\
\hline White blood cell count $\left(10^{9} / 1\right)$, mean \pm SD & $8.1 \pm 3.3$ & $8.9 \pm 2.7$ & $7.3 \pm 2.1$ & $8.1 \pm 2.7$ \\
\hline Neutrophil count $\left(10^{9} / 1\right)$, mean $\pm \mathrm{SD}$ & $5.6 \pm 3.3$ & $6.1 \pm 3.0$ & $4.7 \pm 1.7$ & $5.6 \pm 3.1$ \\
\hline
\end{tabular}

in arms $\mathrm{A}$ and $\mathrm{B}$ of this trial were combined for the purposes of this analysis. The number of patients required was 39 patients per arm, for a total of 117 patients, with the null hypothesis being rejected if at least 34 of 39 patients $(87 \%)$ received $85 \%$ of the overall RDI in any of the treatment arms. Twice as many patients were randomized to the $\mathrm{dd}$ arms, to maximise the information obtained in these experimental arms.

\section{Statistical analysis}

Summary statistics were calculated for RDI and $\mathrm{DI}_{\text {ref }}$ (mean, standard deviation, percentage of patients). $95 \%$ confidence intervals were calculated for the percentage of patients who achieved RDI $\geq 85 \%$, based on the binomial distribution. Dose intensity is given as a proportion of the intended schedule (defined per arm) and was calculated assuming that each component of the chemotherapy schedule is equipotent.

Differences in the incidence of Grade 3-4 neutropenia and febrile neutropenia between $\mathrm{dd}$ and conventional therapy were evaluated using Fisher's Exact Test.

\section{Results}

\section{Patients}

Enrolment took place from 22 September 2005 to 18 July 2006. Baseline characteristics and disease status are shown in Table 1: for those parameters relevant to the primary endpoint (age, white blood cell count) and for the tumour parameters, there were no major imbalances. Overall, $96 \%$ of patients completed the study: $100 \%$ (19/19), 95\% (19/ 20), 97\% (38/39) and 92\% (36/39) in Arms A, B, C and D, respectively. Of the five withdrawals, four were related to adverse events (perineal abscess, wound problem, mucositis and pharyngitis/gastritis) and one (Arm D) to the physician's decision. All but one of the withdrawals (Arm D) occurred in the last cycle of chemotherapy.

\section{Chemotherapy dose delivery}

Of patients receiving the conventional dose regimens, 12 (31\%) received pegfilgrastim secondary prophylaxis. In total, 109 patients (93\%) achieved the primary endpoint 


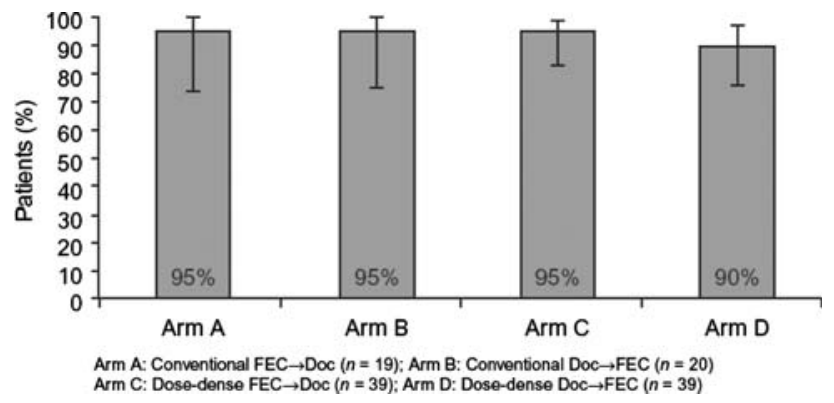

Fig. 2 Percentage of patients achieving RDI $\geq 85 \%$ (primary endpoint). Error bars represent $95 \%$ confidence intervals

(RDI $\geq 85 \%$ ) (Fig. 2), with $78 \%$ of patients $(n=91)$ achieving an RDI $\geq 95 \%$. Only one patient (Arm D) achieved an RDI $<70 \%$. Mean $( \pm$ SD) RDIs were $97.1 \pm$ $6.6 \%, 98.1 \pm 4.2 \%, 96.4 \pm 6.1 \%$ and $96.7 \pm 10.5 \%$ in Arms A, B, C and D, respectively.

As noted above, $96 \%$ of patients completed all cycles of chemotherapy, and only one patient (Arm D) missed more than one cycle, completing 3 out of 8 cycles before study withdrawal. Cumulative doses for all agents, plus for FEC and Doc, are shown in Table 2. Most patients achieved the target cumulative dose for Doc ( $\geq 97.5 \%$ of intended dose) and FEC ( $\geq 97.5 \%$ of intended dose), as well as for all agents combined ( $\geq 99 \%$ of intended dose) (Fig. 3). Analysis of $\mathrm{DI}_{\text {ref }}$ showed that patients in the dd arms received a significantly higher dose intensity than those in the conventional arms $(P<0.001)$ (Table 3$)$.

Dose delays (all agents) occurred in 34 patients (29\%), although only 6 of 849 cycles were delayed by more than 3 days. The most common reasons for delay were practical considerations such as social and logistical reasons (including scheduled dosing falling on a weekend), and protocol deviations. No patient experienced a dose delay as a result of febrile neutropenia (Table 4). Overall, dose delays occurred more frequently in Arm $\mathrm{C}$ than in the other treatment arms, leading to a numerically higher rate of dose delay in patients who received dd treatment compared with those who received conventional treatment (Table 3).

Dose reductions (all agents) occurred in 14 patients (12\%) (Table 3), with most reductions $(n=8)$ involving

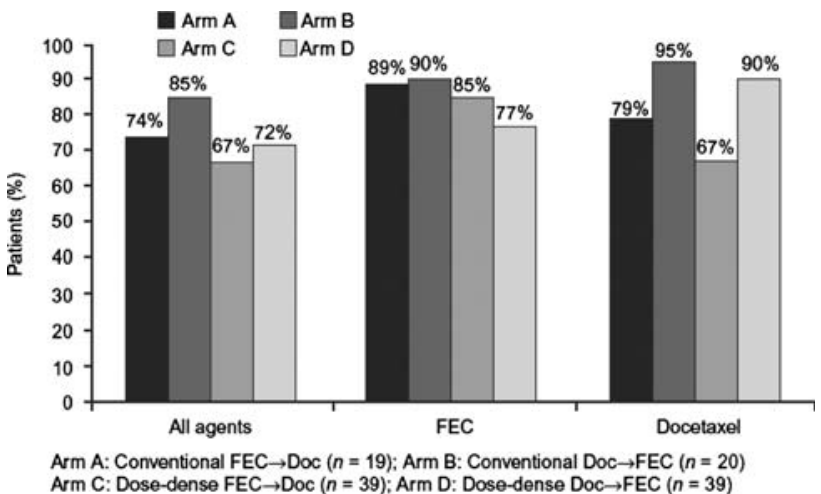

Fig 3 Percentage of patients achieving target cumulative doses of study drugs (defined as $\geq 97.5 \%$ of the intended dose for Doc and FEC, and $\geq 99 \%$ for all agents combined)

non-haematological toxicity with dd Doc given after FEC (Table 4). No dose reduction was the result of febrile neutropenia. Doc reductions were numerically more frequent with dd treatment (13\% vs. $8 \%$ with conventional treatment), and when given second in the chemotherapy sequence (17\% vs. $5 \%$ when given first); most reductions $(n=7)$ were related to skin toxicity (Table 4). Of 849 total cycles of chemotherapy carried out during the study, 42 (5\%) were associated with a dose delay and 41 (5\%) with dose reduction.

\section{Tolerability}

The most important and relevant adverse events considered by the investigators to be induced by treatment and with an incidence of $\geq 15 \%$ in any treatment arm or with a difference of $\geq 10 \%$ between any two treatment arms are shown in Table 5. A number of notable differences between the conventional and dd arms were observed, including a higher incidence of neutropenia in the conventional groups, particularly when FEC was given first in the chemotherapy sequence. There were also higher incidences of fatigue, dry mouth, dizziness and increased lachrymation (Grade 1-2 only) in the dd arms. In addition, there was a higher incidence of myalgia in the groups in which Doc was given first in the chemotherapy sequence. Other notable findings

Table 2 Mean $( \pm \mathrm{SD})$ cumulative dose $\left(\mathrm{mg} / \mathrm{m}^{2}\right)$ of treatment regimens

\begin{tabular}{|c|c|c|c|c|}
\hline & \multicolumn{2}{|l|}{ Conventional } & \multicolumn{2}{|l|}{ Dose-dense } \\
\hline & $\begin{array}{l}\text { A } \\
\text { FEC-Doc }(n=19)\end{array}$ & $\begin{array}{l}\text { B } \\
\text { Doc-FEC }(n=20)\end{array}$ & $\begin{array}{l}\text { C } \\
\text { FEC-Doc }(n=39)\end{array}$ & $\begin{array}{l}\mathrm{D} \\
\text { Doc-FEC }(n=39)\end{array}$ \\
\hline All agents & $3539 \pm 194$ & $3539 \pm 251$ & $3565 \pm 75$ & $3436 \pm 565$ \\
\hline FEC $^{\mathrm{a}}$ & $3247 \pm 177$ & $3241 \pm 251$ & $3275 \pm 74$ & $3223 \pm 199$ \\
\hline Docetaxel & $292.1 \pm 20.0$ & $297.4 \pm 11.5$ & $289.9 \pm 26.4$ & $296.1 \pm 14.9$ \\
\hline
\end{tabular}

a Three drugs taken together; all three drugs were reduced equally by $25 \%$ (conventional) or 20\%(dose-dense) in case of dose reduction 
Table 3 Mean $\mathrm{DI}_{\text {ref }}$, dose reductions and dose delays

\begin{tabular}{|c|c|c|c|c|c|c|c|c|c|c|}
\hline & \multicolumn{2}{|c|}{ Conventional } & \multicolumn{2}{|l|}{ Dose-dense } & \multirow{2}{*}{$\begin{array}{l}\text { Pooled } \\
\text { conventional } \\
\mathrm{A}+\mathrm{B} \\
(n=39)\end{array}$} & \multirow{2}{*}{$\begin{array}{l}\text { Pooled } \\
\text { dose-dense } \\
\mathrm{C}+\mathrm{D} \\
(n=78)\end{array}$} & \multirow{2}{*}{$\begin{array}{l}P \\
\text { value }\end{array}$} & \multirow{2}{*}{$\begin{array}{l}\text { Pooled } \\
\text { FEC first } \\
\text { A }+ \text { C } \\
(n=58)\end{array}$} & \multirow{2}{*}{$\begin{array}{l}\text { Pooled } \\
\text { Doc first } \\
\text { B + D } \\
(n=59)\end{array}$} & \multirow{2}{*}{$\begin{array}{l}P \\
\text { value }\end{array}$} \\
\hline & $\begin{array}{l}\text { A } \\
\text { FEC-Doc } \\
(n=19)\end{array}$ & $\begin{array}{l}\text { B } \\
\text { Doc-FEC } \\
(n=20)\end{array}$ & $\begin{array}{l}\text { C } \\
\text { FEC-Doc } \\
(n=39)\end{array}$ & $\begin{array}{l}\text { D } \\
\text { Doc-FEC } \\
(n=39)\end{array}$ & & & & & & \\
\hline \multicolumn{11}{|l|}{ Mean $D I_{r e f}^{a}$} \\
\hline Docetaxel & 97 & 99 & 108 & 111 & 98 & 109 & $<0.001$ & 104 & 107 & 0.170 \\
\hline FEC $^{\mathrm{b}}$ & 97 & 97 & 146 & 143 & 97 & 144 & $<0.001$ & 130 & 127 & 0.620 \\
\hline \multicolumn{11}{|c|}{ Dose reductions, $n(\%)$} \\
\hline Docetaxel & $2(11)$ & $1(5)$ & $8(21)$ & $2(5)$ & $3(8)$ & $10(13)$ & 0.540 & $10(17)$ & $3(5)$ & 0.043 \\
\hline $\mathrm{FEC}^{\mathrm{b}}$ & $1(5)$ & 0 & $1(3)$ & $2(5)$ & $1(3)$ & $3(4)$ & 1.000 & $2(5)$ & $2(3)$ & 1.000 \\
\hline $\begin{array}{l}\text { Dose } \\
\text { delays, } n \\
(\%)\end{array}$ & $3(16)$ & $5(25)$ & $17(44)$ & $9(23)$ & $8(21)$ & $26(33)$ & 0.196 & $20(34)$ & $14(24)$ & 0.226 \\
\hline
\end{tabular}

${ }^{a}$ The reference value is defined as the dose intensity achieved in Arm A or B for a patient who received all intended doses with no cycle delay or dose reduction. This reference value is defined as the $100 \%$ reference

b The reference value for FEC is the mean of the reference values of the three components of FEC

Table 4 Reasons specified for delay or dose reduction of chemotherapy during the study, expressed as number $(\%)$ of patients ${ }^{\mathrm{a}}$

\begin{tabular}{|c|c|c|c|c|}
\hline \multirow[t]{2}{*}{ Specified reason $^{\mathrm{b}}$} & \multicolumn{2}{|l|}{ Conventional } & \multicolumn{2}{|l|}{ Dose-dense } \\
\hline & $\begin{array}{l}\text { A } \\
\text { FEC-Doc }(n=19)\end{array}$ & $\begin{array}{l}\text { B } \\
\text { Doc-FEC }(n=20)\end{array}$ & $\begin{array}{l}\text { C } \\
\text { FEC-Doc }(n=39)\end{array}$ & $\begin{array}{l}\text { D } \\
\text { Doc-FEC }(n=39)\end{array}$ \\
\hline Dose delay & $3(16)$ & $5(25)$ & $17(44)$ & $9(23)$ \\
\hline Neutropenia ${ }^{c}$ & $2(11)$ & 0 & $4(10)$ & $5(13)$ \\
\hline \multicolumn{5}{|l|}{ Other haematological toxicity } \\
\hline Leucopenia and nail changes & 0 & $1(5)$ & 0 & 0 \\
\hline Anaemia & 0 & 0 & 0 & $1(3)$ \\
\hline Non-haematological reason $^{\mathrm{a}}$ & $1(5)$ & $4(20)$ & $15(38)$ & $4(10)$ \\
\hline Non-medical reasons (e.g., social or logistical) & $1(5)$ & $3(15)$ & $11(28)$ & $2(5)$ \\
\hline Non-haematological toxicity & 0 & 0 & $5(13)$ & $2(5)$ \\
\hline Cold & 0 & $1(5)$ & 0 & 0 \\
\hline Dose reduction-docetaxel & $2(11)$ & $1(5)$ & $8(21)$ & $2(5)$ \\
\hline Neutropenia ${ }^{c}$ & $1(5)$ & 0 & 0 & 0 \\
\hline \multicolumn{5}{|l|}{ Non-haematological reason } \\
\hline Myalgia & $1(5)$ & $1(5)$ & 0 & $1(3)$ \\
\hline Fatigue & 0 & 0 & $2(5)$ & 0 \\
\hline Skin toxicity ${ }^{\mathrm{d}}$ & 0 & 0 & $6(15)$ & $1(3)$ \\
\hline Stomatitis & 0 & 0 & $1(3)$ & 0 \\
\hline Nausea & 0 & 0 & $1(3)$ & 0 \\
\hline Dose reduction-FEC & $1(5)$ & 0 & $1(3)$ & $2(5)$ \\
\hline Neutropenia $^{c}$ & $1(5)$ & 0 & $1(3)$ & $1(3)$ \\
\hline \multicolumn{5}{|l|}{ Non-haematological reason } \\
\hline Protocol violation & $1(5)$ & 0 & 0 & 0 \\
\hline Fatigue & 0 & 0 & 0 & $1(3)$ \\
\hline Anorexia & 0 & 0 & 0 & $1(3)$ \\
\hline
\end{tabular}

${ }^{a}$ Some patients had more than one dose delay or dose reduction attributed to different causes; all causes are mentioned

b Patients could specify more than one reason for dose delay or reduction

c Not including febrile neutropenia

${ }^{\mathrm{d}}$ Including hand-foot syndrome and rash 
Table 5 Key adverse events considered to be related to treatment with $\geq 15 \%$ incidence in any treatment arm or $\geq 10 \%$ difference between any two treatment arms

\begin{tabular}{|c|c|c|c|c|}
\hline \multirow[t]{2}{*}{ Adverse event, $n(\%)$} & \multicolumn{2}{|l|}{ Conventional } & \multicolumn{2}{|l|}{ Dose-dense } \\
\hline & $\begin{array}{l}\text { A } \\
\text { FEC-Doc }(n=19)\end{array}$ & $\begin{array}{l}\text { B } \\
\text { Doc-FEC }(n=20)\end{array}$ & $\begin{array}{l}\text { C } \\
\text { FEC-Doc }(n=39)\end{array}$ & $\begin{array}{l}\text { D } \\
\text { Doc-FEC }(n=39)\end{array}$ \\
\hline Anaemia & $9(47)$ & $10(50)$ & $21(54)$ & $25(64)$ \\
\hline Neutropenia & $7(37)$ & $3(15)$ & $6(15)$ & $2(5)$ \\
\hline Febrile neutropenia & 0 & $2(10)$ & 0 & 0 \\
\hline Lachrymation increased & $2(11)$ & $6(30)$ & $16(41)$ & $20(51)$ \\
\hline Nausea & $16(84)$ & $14(70)$ & $32(82)$ & $33(85)$ \\
\hline Vomiting & $12(63)$ & $8(40)$ & $15(38)$ & $13(33)$ \\
\hline Stomatitis/muscosal inflammation & $7(37)$ & $14(70)$ & $20(51)$ & $15(38)$ \\
\hline Constipation & $2(11)$ & $4(20)$ & $17(44)$ & $10(26)$ \\
\hline Diarrhoea & $4(21)$ & $4(20)$ & $13(33)$ & $10(26)$ \\
\hline Dry mouth & $1(5)$ & $1(5)$ & $6(15)$ & $7(18)$ \\
\hline Fatigue & $10(53)$ & $14(70)$ & $34(87)$ & $35(90)$ \\
\hline Oedema & $2(11)$ & $5(25)$ & $5(13)$ & $8(21)$ \\
\hline Infection & $4(21)$ & $1(5)$ & $6(15)$ & $5(13)$ \\
\hline Myalgia & $8(42)$ & $13(65)$ & $17(44)$ & $23(59)$ \\
\hline Paraesthesia & $4(21)$ & $8(40)$ & $17(44)$ & $13(33)$ \\
\hline Dysgeusia & $7(37)$ & $8(40)$ & $11(28)$ & $12(31)$ \\
\hline Headache & 0 & $6(30)$ & $6(15)$ & $6(15)$ \\
\hline Dizziness & 0 & $1(5)$ & $7(18)$ & $4(10)$ \\
\hline Dyspnoea & $1(5)$ & $6(30)$ & $5(13)$ & $10(26)$ \\
\hline Cough & $1(5)$ & $2(10)$ & $11(28)$ & $6(15)$ \\
\hline Nail disorder & $5(26)$ & $3(15)$ & $12(31)$ & $20(51)$ \\
\hline Rash & $1(5)$ & $9(45)$ & $9(23)$ & $15(38)$ \\
\hline Hand-foot syndrome ${ }^{a}$ & $1(5)$ & 0 & $7(18)$ & $6(15)$ \\
\hline
\end{tabular}

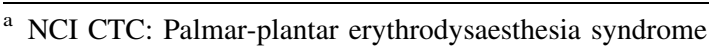

included higher incidences of headache and stomatitis in Group B, and cough in Group C (Table 5).

Treatment-related adverse events of NCI CTC Grade 34 occurred in one third of patients (Table 6). Grade 3-4 neutropenia was significantly more frequent with conventional dosing (Arms A + B: 21\%) compared with the dd arms (Arms $\mathrm{C}+\mathrm{D}: 6 \% ; P=0.03$ ); this was particularly pronounced when FEC was given first (Arm A: $37 \%$; Arm B: 5\%). Grade 3-4 fatigue (0\% vs. $6 \%$ ) and hand-foot syndrome $(0 \%$ vs. $5 \%)$ were also numerically more common in the dd arms. Grade 3-4 febrile neutropenia was reported only in two patients (both in Arm B) and was not significantly different between the conventional and $\mathrm{dd}$ groups $(P=0.109)$. Grade 3-4 skin toxicity was reported in few patients in any study arm, with four patients (3\%) reporting Grade 3 hand-foot syndrome, two patients reporting Grade 3 rash and one patient each reporting Grade 3 erythema and nail disorder. Remarkably, skin toxicity was more frequent in arm $\mathrm{C}$ compared with the other arms (Table 6).

\section{Discussion}

Based on the results of this pilot study, it appears feasible to give a dd regimen of Doc and FEC with growth factor (pegfilgrastim) support. Chemotherapy can be given in either sequence, with most patients in all four treatment arms achieving the target number of chemotherapy cycles with RDI $\geq 85 \%$. Importantly, there was an increase in dose intensity in the dd regimens, particularly for FEC (48\%). This is the first study showing that it is possible to use an FEC regimen with clearly densified dosing compared with $\mathrm{FEC}_{100}$ every 3 weeks, and we believe that the feasibility is largely the result of using an adapted regimen (i.e. $4 \times$ $\mathrm{FEC}_{75}$ every $10-11$ days instead of $3 \times \mathrm{FEC}_{100}$ every 2 weeks, which was shown to be unfeasible in previous studies). There was no important increase in toxicity with the dd regimens, despite the same cumulative dosing in the dd arms compared with the conventional arms. In the FEC part of the dd arms, serious toxicity was limited as demonstrated by the fact that dose reductions were only required 
Table 6 Incidence of Grade 3-4 toxicities (NCI CTC criteria) considered by the investigator to be related to treatment

\begin{tabular}{|c|c|c|c|c|c|c|c|c|}
\hline \multirow[t]{2}{*}{ Adverse event, $n(\%)$} & \multicolumn{2}{|c|}{ Conventional } & \multicolumn{2}{|l|}{ Dose-dense } & \multirow{2}{*}{$\begin{array}{l}\text { Pooled } \\
\text { conventional } \\
\mathrm{A}+\mathrm{B} \\
(n=39)\end{array}$} & \multirow{2}{*}{$\begin{array}{l}\text { Pooled } \\
\text { dose-dense } \\
\mathrm{C}+\mathrm{D} \\
(n=78)\end{array}$} & \multirow{2}{*}{$\begin{array}{l}\text { Pooled } \\
\text { FEC first } \\
\mathrm{A}+\mathrm{C} \\
(n=58)\end{array}$} & \multirow{2}{*}{$\begin{array}{l}\text { Pooled } \\
\text { Doc first } \\
\mathrm{B}+\mathrm{D} \\
(n=59)\end{array}$} \\
\hline & $\begin{array}{l}\text { A } \\
\text { FEC-Doc } \\
(n=19)\end{array}$ & $\begin{array}{l}\text { B } \\
\text { Doc-FEC } \\
(n=20)\end{array}$ & $\begin{array}{l}\text { C } \\
\text { FEC-Doc } \\
(n=39)\end{array}$ & $\begin{array}{l}\text { D } \\
\text { Doc-FEC } \\
(n=39)\end{array}$ & & & & \\
\hline $\begin{array}{l}\text { Any Grade 3-4 treatment- } \\
\text { related adverse event }\end{array}$ & $10(53)$ & $5(25)$ & $15(38)$ & $9(23)$ & $15(38)$ & $24(31)$ & $25(43)$ & $14(24)$ \\
\hline Anaemia & 0 & 0 & 0 & $2(5)$ & 0 & $2(3)$ & 0 & $2(3)$ \\
\hline Febrile neutropenia & 0 & $2(10)$ & 0 & 0 & $2(5)$ & 0 & 0 & $2(3)$ \\
\hline Neutropenia & $7(37)$ & $1(5)$ & $3(8)$ & $2(5)$ & $8(21)$ & $5(6)$ & $10(17)$ & $3(5)$ \\
\hline Abdominal pain upper & 0 & $1(5)$ & 0 & 0 & $1(3)$ & 0 & 0 & $1(2)$ \\
\hline Diarrhoea & $1(5)$ & 0 & $1(3)$ & 0 & $1(3)$ & $1(1)$ & $2(3)$ & 0 \\
\hline Nausea & $1(5)$ & 0 & $2(5)$ & 0 & $1(3)$ & $2(3)$ & $3(5)$ & 0 \\
\hline $\begin{array}{l}\text { Stomatitis/mucosal } \\
\text { inflammation }\end{array}$ & 0 & 0 & $2(5)$ & $2(5)$ & 0 & $4(5)$ & $2(3)$ & $2(3)$ \\
\hline Vomiting & $1(5)$ & 0 & $1(3)$ & 0 & $1(3)$ & $1(1)$ & $2(3)$ & 0 \\
\hline Fatigue/malaise & 0 & 0 & $4(10)$ & $2(5)$ & 0 & $6(8)$ & $4(7)$ & $2(3)$ \\
\hline Infections $^{\mathrm{a}}$ & 0 & $1(5)$ & $1(3)$ & $1(3)$ & $1(3)$ & $2(3)$ & $1(2)$ & $2(3)$ \\
\hline Anorexia & 0 & 0 & $1(3)$ & $1(3)$ & 0 & $2(3)$ & $1(2)$ & $1(3)$ \\
\hline Myalgia & $1(5)$ & $1(5)$ & 0 & $1(3)$ & $2(5)$ & $1(1)$ & $1(2)$ & $2(3)$ \\
\hline Skin disorders ${ }^{\mathrm{b}}$ & 0 & 0 & $6(15)$ & $1(3)$ & 0 & 7 (9) & $6(10)$ & $1(2)$ \\
\hline
\end{tabular}

${ }^{a}$ Includes Campylobacter intestinal infection, perineal abscess and post-operative wound infection

b Includes rash (3), erythema and palmar-plantar erythrodysaesthesia syndrome (hand-foot syndrome) (4)

in 3 out of 78 patients. In previous studies, densifying Doc to $100 \mathrm{mg} / \mathrm{m}^{2}$ every 2 weeks was associated with excessive (skin) toxicity. In the present study, therefore, it was decided to densify Doc only moderately using $75 \mathrm{mg} / \mathrm{m}^{2}$ every 2 weeks, reaching an $11 \%$ increase in dose intensity of Doc. With this adaptation, grade $3-4$ skin toxicity occurred in a small proportion of patients, considerably less than observed in previous dose-densification studies using Doc $100 \mathrm{mg} / \mathrm{m}^{2}$ every 2 weeks $[19,20]$, but seemed dependent on sequence (15\% if FEC first and 3\% if Doc first). Increased lachrymation (Grade 1-2) was also observed, but this is an expected side effect of dd Doc therapy [29].

Delivery of the dd regimens was made possible by pegfilgrastim, preventing any increase in the incidence of neutropenia or febrile neutropenia, and any increase in neutropenia-related dose delays or reductions. It should be noted that reimbursement guidelines in Belgium specify that prophylactic growth factor support can be given in the event of Grade 4 neutropenia (ANC $<0.5 \times 10^{9} / 1$ ) for 5 days as well as in the event of febrile neutropenia. Overall, $31 \%$ of patients receiving conventional chemotherapy also required prophylactic use of pegfilgrastim. Issues relating to administration of growth factors to patients with existing very high leukocyte levels are not fully understood, and there has been one report of patient with a white blood cell count of $123,310 / \mathrm{mm}^{3}$ during GCSF treatment [30]. Administration is unlikely to be harmful, however, as bone marrow is more likely to be in a less active state in patients with high leukocyte levels. In the present study, there was a tendency for white blood cells and neutrophils to increase during dd Doc treatment and decrease during dd FEC treatment (data not shown), although elevation of white blood cell count was generally modest (maximum values, $75,600 / \mathrm{mm}^{3}$ and $71,800 \mathrm{~mm}^{3}$ for white blood cells and neutrophils, respectively). All patients remained asymptomatic, and G-CSF was not discontinued in any patient.

The results of the present study also show that treatment sequence can affect the delivery of chemotherapy, particularly with the dd regimens. Most notably, in the conventional and dd arms, higher doses were possible with the agent/combination delivered first, with numerically higher cumulative Doc doses achieved in patients who received Doc before FEC (Arms B and D). When given first, Doc was also associated with significantly fewer dose reductions and, in the dd arms, this sequence was associated with fewer dose delays. Most dose reductions involved Doc given after FEC, with skin toxicity (e.g. hand-foot syndrome) the most frequently cited cause for reduction. It appears, therefore, that prior administration of anthracyclines increases the (skin) toxicity of docetaxel. The results of the present study are also consistent with a number of previous smaller studies showing that dose sequence can affect treatment tolerability. In a small-scale study 
( $n=33$ ) in patients with metastatic breast cancer, $\mathrm{AC} \rightarrow$ Doc was associated with double the Doc dose intensity compared with Doc $\rightarrow$ AC (median, 28 vs. $14 \mathrm{mg} /$ $\mathrm{m}^{2} /$ week), although patients who received Doc first experienced a higher incidence of Grade 4 neutropenia and febrile neutropenia than those receiving AC first (no prophylactic growth factor support was permitted) [31]. Dosedense Doc $\rightarrow \mathrm{AC}$ and $\mathrm{AC} \rightarrow$ Doc were compared in 56 patients with node-positive breast cancer, with results showing that providing Doc first was associated with a significantly higher Doc RDI (96\% vs. $81 \% ; P=0.02)$, with a numerically lower incidence of dose reductions (17\% vs. $40 \%)$ and dose delays (8\% vs. 16\%) [32]. Interestingly, the RDI of AC chemotherapy was not affected by dose sequence (97\% when given first vs. $98 \%$ when given second; $P=0.48$ ). In a recent study comparing Doc $\rightarrow \mathrm{EC}$ with $\mathrm{EC} \rightarrow$ Doc, delivery of Doc first was associated with fewer dose delays (38\% vs. 53\%) and a lower incidence of Grade 4 neutropenia (29\% vs. 49\%) [33]. Thus it appears that the same conclusion can be drawn from all these studies, namely that providing Doc first in the chemotherapy sequence might improve delivery and decrease the incidence of adverse events when given with appropriate growth factor support.

The present study has a number of strengths. Unlike many previous studies of dd chemotherapy, patients in the present trial received the same cumulative dose of all drugs in the conventional and dd arms. In addition, the use of $4 \times \mathrm{FEC}_{75}$ rather than $3 \times \mathrm{FEC}_{100}$ allowed a decrease in the peak dose, which is correlated with toxicity (particularly nausea and vomiting, as well as cardiotoxicity), thus allowing delivery of FEC every 10-11 days. Moreover, the four-way design allowed assessment of the impact of FEC and Doc dose sequence as well as dose densification. Further research is now needed to confirm the results of this Phase II feasibility study and to investigate the dd FEC-Doc regimens more thoroughly. Long-term follow-up is also required to investigate safety issues. For example, a recent retrospective, hypothesis-generating, database analysis found some evidence that use of G-CSF may be associated with an increase in the risk of leukaemia [34]. The analysis did not, however, take into account chemotherapy dosing, which is also known to increase the risk of secondary malignancy [35]. Several studies with long-term follow-up, however, did not report any increase in the incidence of patients with leukaemia or myelodysplastic syndrome $[15,18]$, and the absolute risk of leukaemia is very small, so the benefits of G-CSF may still outweigh any additional risk [34]. Other adverse events that have been associated with dd regimens include Pneumocystis carinii infection [36] and dyspnoea [37].

More rapid delivery of chemotherapy may be associated with advantages to patients with early-stage breast cancer beyond those of efficacy, and anecdotal evidence suggests that patients prefer the shorter total chemotherapy duration associated with dd regimens. There may, however, be practical problems with a regimen such as the 10-11 day FEC cycle used in the present study. Indeed, the most common reasons for dose delay were logistical factors such as the dosing day falling on a weekend. In an earlier study of chemotherapy using 10-11-day cycles, dose-dense EC/ paclitaxel was shown to be feasible, with the protocol allowing a 2-day window specifically to avoid such logistical issues [12]. Adequate planning before the start of the therapy can prevent problems relating to logistical issues.

Further studies and long-term follow-up in larger patient cohorts are now needed to see if dd FEC/Doc dosing is associated with increased survival benefits over conventional dosing. The benefits of combining dd Doc/FEC with trastuzumab in patients with HER2-positive disease may also merit investigation.

In conclusion, delivery of adjuvant sequential dd FECDoc to patients with breast cancer is feasible with appropriate growth factor support. Notably, the results show that densification of FEC every 10-11 days is possible with pegfilgrastim. In general, Grade 3-4 toxicity was limited and there were no important increases with dd therapy. Further studies are needed to see if this dd regimen confers a survival benefit over conventional delivery. Target doses were achieved more easily in the first chemotherapy cycles of the dd sequence. In particular, dose intensity of Doc decreased and toxicity increased when dd Doc was given after dd FEC. The sequence of drugs might have an impact on dose delivery, intensity and toxicity, and should be explored further.

Acknowledgements This study and manuscript were supported by an unrestricted grant from Amgen (Europe) GmbH. Editorial support was provided by Dr. Daniel Booth.

\section{References}

1. Early Breast Cancer Trialists' Collaborative Group (EBCTCG) (2005) Effects of chemotherapy and hormonal therapy for early breast cancer on recurrence and 15-year survival: an overview of the randomised trials. Lancet 365:1687-1717

2. Bria E, Nistico C, Cuppone F et al (2006) Benefit of taxanes as adjuvant chemotherapy for early breast cancer: pooled analysis of 15,500 patients. Cancer 106:2337-2344

3. Farquhar CM, Marjoribanks J, Lethaby A, Basser R (2007) High dose chemotherapy for poor prognosis breast cancer: systematic review and meta-analysis. Cancer Treat Rev 33:325-337

4. Bonadonna G, Valagussa P, Moliterni A et al (1995) Adjuvant cyclophosphamide, methotrexate, and fluorouracil in node-positive breast cancer: the results of 20 years of follow-up. N Engl J Med 332:901-906

5. Chirivella I, Bermejo B, Insa A et al (2006) Impact of chemotherapy dose-related factors on survival in breast cancer patients treated with adjuvant anthracycline-based chemotherapy. J Clin Oncol 18S:668 
6. Szutowicz E, Radecka B, Dziadziuszko R et al (2006) Relative dose intensity (RDI) relevance in adjuvant CMF chemotherapy of breast cancer. Eur J Cancer Suppl 4:155

7. Budman DR, Berry DA, Cirrincione CT et al (1998) Dose and dose intensity as determinants of outcome in the adjuvant treatment of breast cancer. The Cancer and Leukemia Group B. J Natl Cancer Inst 90:1205-1211

8. Fountzilas G, Papadimitriou C, Aravantinos G et al (2001) Dosedense sequential adjuvant chemotherapy with epirubicin, paclitaxel and CMF in high-risk breast cancer. Oncology 60:214-220

9. Fountzilas G, Papadimitriou C, Dafni U et al (2001) Dose-dense sequential chemotherapy with epirubicin and paclitaxel versus the combination, as first-line chemotherapy, in advanced breast cancer: a randomized study conducted by the Hellenic Cooperative Oncology Group. J Clin Oncol 19:2232-2239

10. Kümmel S, Krocker J, Kohls A et al (2006) Randomised trial: survival benefit and safety of adjuvant dose-dense chemotherapy for node-positive breast cancer. Br J Cancer 94:1237-1244

11. Fountzilas G, Skarlos D, Dafni U et al (2005) Postoperative dosedense sequential chemotherapy with epirubicin, followed by CMF with or without paclitaxel, in patients with high-risk operable breast cancer: a randomized phase III study conducted by the Hellenic Cooperative Oncology Group. Ann Oncol 16:17621771

12. Fornier MN, Seidman AD, Lake D et al (2007) Increased dose density is feasible: a pilot study of adjuvant epirubicin and cyclophosphamide followed by paclitaxel, at 10- or 11-day intervals with filgrastim support in women with breast cancer. Clin Cancer Res 13:223-227

13. Fountzilas G, Pectasides D, Christodoulou C et al (2006) Adjuvant dose-dense sequential chemotherapy with epirubicin, CMF, and weekly docetaxel is feasible and safe in patients with operable breast cancer. Med Oncol 23:479-488

14. Burdette-Radoux S, Wood ME, Olin JJ et al (2007) Phase I/II trial of adjuvant dose-dense docetaxel/epirubicin/cyclophosphamide (TEC) in stage II and III breast cancer. Breast J 13:274-280

15. Citron ML, Berry DA, Cirrincione C et al (2003) Randomized trial of dose-dense versus conventionally scheduled and sequential versus concurrent combination chemotherapy as postoperative adjuvant treatment of node-positive primary breast cancer: first report of Intergroup Trial C9741/Cancer and Leukemia Group B Trial 9741. J Clin Oncol 21:1431-1439

16. Jones SE, Erban J, Overmoyer B et al (2005) Randomized phase III study of docetaxel compared with paclitaxel in metastatic breast cancer. J Clin Oncol 23:5542-5551

17. French Adjuvant Study Group (2001) Benefit of a high-dose epirubicin regimen in adjuvant chemotherapy for node-positive breast cancer patients with poor prognostic factors: 5-year followup results of French Adjuvant Study Group 05 randomized trial. J Clin Oncol 19:602-611

18. Venturini M, Del ML, Aitini E et al (2005) Dose-dense adjuvant chemotherapy in early breast cancer patients: results from a randomized trial. J Natl Cancer Inst 97:1724-1733

19. Dang CT (2006) Drug treatments for adjuvant chemotherapy in breast cancer: recent trials and future directions. Expert Rev Anticancer Ther 6:427-436

20. Dang CT, D'Andrea GM, Moynahan ME et al (2004) Phase II study of feasibility of dose-dense FEC followed by alternating weekly taxanes in high-risk, four or more node-positive breast cancer. Clin Cancer Res 10:5754-5761

21. Legha SS, Benjamin RS, Mackay B et al (1982) Reduction of doxorubicin cardiotoxicity by prolonged continuous intravenous infusion. Ann Intern Med 96:133-139
22. Jackisch C, von Minckwitz G, Eidtmann H et al (2002) Dosedense biweekly doxorubicin/docetaxel versus sequential neoadjuvant chemotherapy with doxorubicin/cyclophosphamide/ docetaxel in operable breast cancer: second interim analysis. Clin Breast Cancer 3:276-280

23. Schwartz J, Domchek SM, Hwang WT et al (2005) Evaluation of anemia, neutropenia and skin toxicities in standard or dose-dense doxorubicin/cyclophosphamide (AC)-paclitaxel or docetaxel adjuvant chemotherapy in breast cancer. Ann Oncol 16:247-252

24. Fumoleau P, Brain E, Delozier T et al (2005) Adjuvant dosedense ( 3 FEC 100 followed by 3 docetaxel every 2 weeks) regimen is not feasible. Results of FNCLCC-PACS 06 study. Poster presented at the 28th annual San Antonio breast cancer symposium, San Antonio, TX, 8-11 Dec 2005

25. Bonadonna G, Zambetti M, Moliterni A et al (2004) Clinical relevance of different sequencing of doxorubicin and cyclophosphamide, methotrexate, and fluorouracil in operable breast cancer. J Clin Oncol 22:1614-1620

26. Chan S, Friedrichs K, Noel D et al (1999) Prospective randomized trial of docetaxel versus doxorubicin in patients with metastatic breast cancer. J Clin Oncol 17:2341-2354

27. Oken MM, Creech RH, Tormey DC et al (1982) Toxicity and response criteria of the Eastern Cooperative Oncology Group. Am J Clin Oncol 5:649-655

28. Cancer Therapy Evaluation Program (2003) Common terminology criteria for adverse events index. Version 3.0. National Cancer Institute, Bethesda, MD

29. Engels FK, Verweij J (2005) Docetaxel administration schedule: from fever to tears? A review of randomised studies. Eur J Cancer 41:1117-1126

30. Wolff AC, Jones RJ, Davidson NE et al (2006) Myeloid toxicity in breast cancer patients receiving adjuvant chemotherapy with pegfilgrastim support. J Clin Oncol 24:2392-2394

31. Perez EA, Geeraerts L, Suman VJ et al (2002) A randomized phase II study of sequential docetaxel and doxorubicin/cyclophosphamide in patients with metastatic breast cancer. Ann Oncol 13:1225-1235

32. Puhalla S, Young D, Ottman S et al (2006) Phase II randomized adjuvant trial of dose-dense docetaxel (DOC) before or after doxorubicin/cyclophosphamide (AC) in axillary node-positive breast cancer. Poster presented at the 29th annual San Antonio breast cancer symposium, San Antonio, TX, 14-17 Dec 2006

33. Piedbois P, Serin D, Priou F et al (2007) Dose-dense adjuvant chemotherapy in node-positive breast cancer: docetaxel followed by epirubicin/cyclophosphamide (T/EC), or the reverse sequence $(\mathrm{EC} / \mathrm{T})$, every 2 weeks, versus docetaxel, epirubicin and cyclophosphamide (TEC) every 3 weeks. AERO B03 randomized phase II study. Ann Oncol 18:52-57

34. Hershman D, Neugut AI, Jacobson JS et al (2007) Acute myeloid leukemia or myelodysplastic syndrome following use of granulocyte colony-stimulating factors during breast cancer adjuvant chemotherapy. J Natl Cancer Inst 99:196-205

35. Praga C (2005) Risk of acute myeloid leukemia and myelodysplastic syndrome in trials of adjuvant epirubicin for early breast cancer: correlation with doses of epirubicin and cyclophosphamide. J Clin Oncol 23:4179-4191

36. Tolaney SM, Partridge AH, Sheib RG et al (2006) Pneumocystis carinii pneumonia during dose-dense chemotherapy for breast cancer. J Clin Oncol 24:5330-5331

37. Schneeweiss A, Schuetz F, Rudlowski C et al (2005) Dose-dense primary systemic chemotherapy with gemcitabine plus epirubicin sequentially followed by docetaxel for early breast cancer: final results of a phase I/II trial. Anticancer Drugs 16:1023-1028 